\title{
User Experience Design Manifesto
}

\author{
Paulo Maldonado ${ }^{1,2,3}$ \\ ${ }^{1}$ Universidades Lusíada, Centro de Investigação em Território, Arquitetura e Design, \\ (CITAD), Rua da Junqueira, 188-198, 1349-001 Lisboa, Portugal \\ ${ }^{2}$ Universidade de Lisboa, Faculdade de Arquitetura, Centro de Investigação em Arquitetura, \\ Urbanismo e Design (CIAUD), Rua Sá Nogueira, Polo Universitário, Alto da Ajuda, \\ 1349-055 Lisboa, Portugal \\ ${ }^{3}$ Universidade de Évora, Escola de Artes, Departamento de Artes Visuais e Design, Centro de \\ História de Arte e Investigação Avançada (CHAIA), Palácio do Vimioso, Largo Marquês de \\ Marialva 8, 7000-809 Évora, Portugal \\ paulomaldonado@inspaedia.com
}

\begin{abstract}
The rapid change of the elements of context requires an urgent reflection on "Experience" and "Meaning with Value". The aim of this article is to critically review the User Experience Design (UXD) as a disciplinary field, and contribute by a Manifesto to an inspiring vision of the future. Some authors will be reviewed in order to list and discuss the different ideas to redefine the desirable skills to an enlightened practice and to influence a new ethos of "Be Innovation" to a better world. The article retrieves and revisits a Design Manifesto made on the basis of a strategic vision for Design based on distinctive design competencies. This Manifesto was in the origin of the platform www.inspaedia.com.
\end{abstract}

Keywords: Manifesto $\cdot$ User Experience Design $\cdot$ Design $\cdot$ Innovation $\cdot$ Strategic Vision · Distinctive Design Competencies

\section{About a strategic vision for design}

20 years is the temporal arc that separates us from the reflection that in the scope of the research project of our masters degree in Design with the title «Design: a strategic vision» [1] was at the origin of the platform Inspædia (www.inspaedia.com). In this article we revisit this reflection and the Manifesto that resulted from it in the sense of provoking the discussion about the construction of the research processes, summoning, complementarily, to the reading of other publications that we made on the subject User Experience Design underlying the process of research and development of the Inspædia platform $[2,3,4,5,6,7,8,9,10,11]$.

With regard to a strategic vision for Design, we used the form of a manifesto ${ }^{1}$ as a matrix to communicate the concept we designate by new «distinctive design

\footnotetext{
${ }^{1}$ Charles Handy suggests the use of the words «meta» or «manifesto» when one considers the word «vision» too pompous [12], probably because he mistrusts the connotation of the word
} 
competencies», ${ }^{2}$ starting from the «interaction between the organization of creativity, the management of knowledge and the impact of new technologies» ${ }^{3}$ and the concept of «utopia as a strategy», which fights the capitalist / consumerist model, replacing it with an «ideology of constructors» (Lester Thurow). ${ }^{4}$ We advocated a central ideology, a vision of the future and its alignment with implementation, following the recommendations of James Collins. The Manifesto was not, nor was it meant to be, a final document, because such a position was inconsistent with the ideology that supported it. The collective knowledge resulting from the dynamics of interactivity would be in charge of perfecting the proposed model, introducing to it, continuously, the adjustments that the partners considered necessary. Thus, the idea, the process and the results would be, in themselves, Design.

In 1975, N. Cross, when considering the emergence of a post-industrial society, wondered about the possible need to invent a new Design process [16] in the near future. He referred to Architecture and was far from suspecting the profound changes to occur in the production-consumption process. Simultaneously, other questions arose as to which objects to project in the future and which perspectives to carry out the professional activity. Thus, in 1973, H. Kraus predicted that the industrial designer of the future would stop designing objects of use in close collaboration with other experts to create «jobs, man-machine systems, complete organizations».

«vision» in the wake of the German idealist tradition «conception of the world». We have therefore proposed transposing the term «manifest» to a less usual form (since it is usually applied to a cultural, social or political area): we put it at the service of presenting the proposed concept, in order to incite, summon participation.

${ }^{2}$ Design is a structuring factor of distinctive competence because the design process we reinvented was underpinning the business idea we proposed.

${ }^{3}$ By the way, see the following excerpt from an interview with John Kao (JK), led by Jorge Nascimento Rodrigues (JNR): «JNR [...] if we are moving from the era of competitive advantage to the era of creative advantage is it that Michael Porter and the other competition theorists were wrong? JK - [...] they all talk about creativity ... but they do not say «what» and «how» to do, that is, how to manage creativity. The key issue is no longer to consider creativity as a priority, but to know how to create and manage it systematically. [Jamming] is at the intersection of three axes: the organization of creativity; the management of knowledge; and the impact of new technologies. The last two axes facilitate the first. [...] Design is something established, in architecture, in products, in graphics. It needs to be extended to business. [...] Do not we talk about the design of the organization, the design of the intranets, the design of a culture of collaboration? So the business leader has to look at himself as a designer.» [13] For an identical perspective, see Michael Hammer [14].

${ }^{4}$ It proposes utopia as a strategy, which means instituting a revolutionary process of vision, in order to allow the flourishing of democracy and the reconstruction of a more just and humanized society. He argues that the capitalist / consumerist model will tend towards a «builder ideology», in which governments will play an important but no more important role; the heroes of the future will be able to build the new industries (the «gray-mass industries»). This coordinated action will focus on «human skills, technologies and basic infrastructures» [15]. This author recovers the schumperterian sense of the term «entrepreneur» and enriches it: the new entrepreneur is a «builder» whose skills are based on knowhow and knowledge. 
Retracting in time but still in the 70s, T. A. Markus (1972) typified three modes of performance and socio-professional framing of the designer: ${ }^{5}$

«The first role is essentially conservative, centred around the continue dominance of the professional institutions. In such a role the designer remains unconnected with either clients or makers. [...] The opposite to this conservative aproach is actively to seek changes in society which would result in the end of professionalism as we know it. Such a revolutionary aproach would lead the designer to associate himself directly with user groups. Since this kind of designer is also likely to believe in a decentralised society he would be happiest when dealing with the disadvantage, such as the tenents of slum clearence areas, or the revolutionary forsakes his position of independence and power. He no longer sees himself as a leader but as a campaigner and spokesman. [...] The thirth, middle, path lies between these two extremes, and is much more difficult to identify except in vague terms. In this role the designer remains a professionally qualified specialist but tries to envolve the users of his design in his process. These more participatory approaches to design may include a whole range of relatively new techniques, ranging the public inquiry through gaming and simulation to the recent computer-aided design procedures. [...] Designers following this approach are likely to have abandoned the traditional idea that the individual designer is dominant in the process, but they may still believe they have some specialised decision making skills to offer». [16]

Contrary to what was said by T. A. Markus in the 1970s, the second modality appears today (1997) to be extremely timely. Before we realize its potentialities and interest for the strategic vision we have proposed, we have tried to disassemble its argument. Markus considered it very risky for the professional survival of the designers and, for that reason, did not recommend it. He feared for «lose his hand» by opening the creative process «to more voices». Contexts and opportunities had changed radically, but it was not only for this reason that we were convinced that the future of the designer's profession would be in the sharing of decisions, even the project decisions. The digital economy has revolutionized this logic by creating the conditions for consumers to be present in the various moments of the process, from conception and production, to the marketing and distribution of products and services. However, it is not only for this reason that we intend to include them in the process and remunerate them, depending on their participation, it is not only because of this pressure that we will have to go to the trailer for fear of «losing our hand».

Resuming the problem of participation and the socio-professional framework, the strategic vision that we proposed for the design opened up much more voices than the

\footnotetext{
${ }^{5}$ The following text refers to the professional activity of the architect. In the English language, the word design applies to any project activity. While acknowledging specifics in industrial design, also recognized by those who understand design in this broad sense, we propose that the reader extrapolate the thinking of Markus to the industrial design and the pursuit of the professional activity of designers working for the Industry. We refer to Tomás Maldonado and to the reexamination of his 1972 reexamination [17] and to Victor Margolin [18], among other authors and works that could be called for the most consistent attempts to define the term design.
} 
claimed by T. A. Markus. ${ }^{6}$ The new technologies allowed it and the brand-new digital economy required it, otherwise major opportunities would be lost.

The profound transformations that took place led to a reflection on the design scenarios (ways of designing and designers relating to customers and users / consumers).

The business idea that we proposed resulted from the observation, interpretation, reinvention and application ${ }^{7}$ of a vast field of theories and practices that we tried to expose in the possible detail. It was based on the concept of «global thinking and action», ${ }^{8}$ centered on the new potentialities that were part of the so-called digital age. Bet on creativity, correlative of flexibility and competence. ${ }^{9}$ It was not a panacea or a magic word but an imperative that stemmed from the need to change.

\footnotetext{
${ }^{6}$ The underlying motivations have nothing to do with those that animated the experiences called for in the text: contexts (political, social, economic) and possibilities were, at the time, completely different. The proposed way to ensure the participation of allies may face difficulties (which we will try to identify later). However, it is not part of the same type of constraints that guided some of the experiences previously mentioned: the process will be totally open and participated, the access is spontaneous, reason why it seems to be difficult for us to have room for paternalistic or authoritarian attitudes. The contributions of the partners are worth by themselves and not by the importance of their person or personality.

${ }^{7}$ Our research did not coincide with the application of the idea, so only then will it be finished (if it ever will). In the digital state, the investigation does not precede the launch. It is part of the launch, i. and. integrates with the launch-and-learn strategy [19].

${ }^{8}$ For an opinion to the contrary, but that is exactly on the same assumption - the connectivity that the Net allows (see Chuck Martin's positioning, which coincides with John Naisbitt's, «local thinking and global action») in answering the question of Jorge Nascimento Rodrigues to Chuck Martin: In the 80 's, we learned to «think global and act locally». Now he tells us that we must «think local and global action» an idea also advocated by John Naisbitt. Why this inversion? Answer: «because the Net makes this possible. This is now a mere evidence.» [20].

${ }^{9}$ «Today all companies are looking for a new advantage, delicate and dangerous, but vital: that of creativity. Global competition increasingly depends on the ability of nations to mobilize their ideas and talents to create creative organizations. [...] Creativity begins with the generation of ideas ... It is crucial to import new data from the outside. is to diffuse and impregnate by the company an aspiration of creativity ... The desire for creativity must become the norm and not the exception .... Non-creative companies have three possibilities: to buy innovative companies; ally with them; or buy stars. Appealing to outside actors to participate in a specific project has become commonplace... It is up to the leaders to establish a new «temporary culture», indispensable for refreshing new ideas and ideas. [...] The new information technologies favor the generation of ideas by developing access to knowledge and informal exchanges. [...] As in jazz, cyberspace is a meritocracy of talents that are both competitive and cooperative. Power no longer comes from knowledge - to which everyone has access - but from the creativity extended by the network. [...] Companies of the future can design their structure and culture in a flexible way, in function of their creative projects. It will only be the sum of your ideas, knowledge and abilities. The organization of the future will be like a factory of ideas, whose starting point is the unknown. You do not know the products you are going to build, nor the competitors you are going to face: it recreates itself permanently. The leader must manage contrary tendencies like freedom versus discipline, fixed goals versus flexibility, collective responsibilities, safety versus risk, acquisition versus innovation, experience versus novelty, and normalization. experimentation.» [13]
} 
It was intended to find / define a context ${ }^{10}$ for the design process (actors and environment) ${ }^{11} 12$ and the motivations and capacities for an interaction strategy (culture, information and knowledge). That is to say, based on a global strategic vision, we intend to carefully select the (dynamic, flexible and creative) ${ }^{13}$ principles capable of determining the most appropriate competences for a design process («distinctive competencies») ${ }^{14}$ with a well defined objective: without innovation necessarily having to go through the invention of new technologies. However, there is no innovation without creativity. The epochal context seemed to propitiate, ${ }^{15}$ at the outset, the success of proposals such as ours.

\footnotetext{
${ }^{10}$ According to Chuck Martin, in the digital state is the context that determines value, not content: «context is the combination of all the surrounding factors: time; the place; the relevance of the content; the technology used. It is fluid, malleable, reactive, and interactive, just like the Net itself.» [20]

${ }^{11}$ Or «procedural paradigm», advocated by Tom Peters and also by Kees Van Der Heijden: «Success is more closely related to a good process than to the discovery of an «optimal strategy». [21]

${ }^{12}$ Knut Holt thus synthesizes the process of visionary design: «when you invent something realy new, you create a need. The big trick is not to invent to satisfy a need - anybody can do that. The trick is to recognize that need that people do not realize is a need.» [22]. This optimism is qualified that we refrain from adjectivizing out of respect for all those who suffer the dissatisfaction of vital needs and for those who continue to find in them their reason for being.

${ }^{13}$ «Soozoo (criativity) is the new battle cry, companies strive to gain or retain their share of the global market.» [22].

${ }^{14}$ Gary Hamel prefers the concept of «distinctive competencies» rather than «strategic business units». [23]. Its scope fits better with our idea. «Three business strategies have to interface with designing: develop market / user understanding thoughly before design development; focus on commercially viable translation of ideas, i.e. innovation for successful commercial products; design a well-integrated organization to support product development in the milieu of ever changing conditions, with product systems or cascading development from one product to the next.» [22]. Still on «distinctive competences».

${ }^{15}$ In ostinato, John Kao explains why our era is that of creativity. In his opinion, there are eight great arguments that justify it: «this is the age of creativity because that's where information technology wants to go next. [...] because it's the age of knowlege. And in an era of prizes knowledge, creativity adds value to knowledge and makes it progressively more useful. [...] because companies are increasingly forced to rapidly reinvent themselves to achieve growth. [...] because many workers today feel creative jobs, and talented people are mobile as never before. [...] because of the new primacy of design. [...] because there has been a change of regime in the marketplace. The customer is the boss now - discerning, demanding, and no more loyal than he or she has to be. The new boss has only one question: So what are you going to do for me tomorrow? Only creativity can give the answer. [...] because the subtext of global competition is increasingly about a nation's ability to mobilize its ideas, talents, and creative organizations. A company that ignores the global creativity map is spurning an important set of strategic considerations. [...] This is the age of creativity because management is transforming its role from controller to emancipator - of creativity. This is the new managerial mind - set.» [24].
} 


\section{Manifesto}

\section{The process is open (free).}

It is based on the connectivity that the Internet allows and empower.

\section{There are no business or business areas defined at the outset.}

Herein lies part of the innovation component that we intend to introduce. Distinctive competence ${ }^{16}$ will be what it has to be, what it wants to be. What will determine the process of definition will be a network of people that interact for this purpose / common goal. As a consequence, preferred business or business areas are not initially defined.

\section{The distinctive competence is locus free.}

There are no physical or virtual barriers between research, development, production, distribution and consumption. Anyone can be anywhere and practically at the same time. There is no rigid sequence of actions between the moment the idea arises and the consumption of the «functionalities» created. ${ }^{17}$ On the other hand, it is hoped to promote an interaction of events, generating other events.

\section{It is not initiated through a pre-established or existing organization.}

This principle stems from a non a priori definition of the distinctive competencies to be developed. The alliance of individuals is an initial datum but not an end in itself, only a mean. The definition and configuration of the group / partners will be made later: the proposed model approximates the (amplified) concept of «virtual organization» (Francis Fukuiama), which allows introducing a great dynamics and flexibility in the process.

\section{Intelligence acts on information, transforming it into knowledge.}

The partners involved in the process (knowledge workers), interacting in a network, contribute to transform the information available in the network into knowledge. The grouping of different knowledge can be organized into thematic clusters to enhance creativity, using the virtualities inherent in the (digital) concept of «pulling».

6. Innovation is based on the constant and elaborate exploitation of intelligence and creativity. ${ }^{18}$

\footnotetext{
${ }^{16}$ From now on, the concept of «distinctive competence» often arises as a substitute for «business areas» or «strategic business units» because it conveys the necessary breadth to the idea's development. Since design is the process underlying the definition of distinctive competence (s), it is the very design process (reinvented) that interests us.

${ }^{17}$ The term «functionality» replaces «products and services». Flexibility and recurrence underlie the proposed model. «The ultimatly successful U.S. organizations abandoned the step-by-step model of $R \& D$, created dedicated integration teams, and shrank the role of their research and manufacturing organizations in choosing technologies.» [25]

${ }^{18}$ On the new challenges to making information operational, Peter Drucker adds: «The development of rigorous methods for gathering and analyzing outsider information will encreasingly become a major challenge for business and for information experts.» [26]
} 
The aim is to achieve innovation through the development of new ideas, stimulation of intelligence and individual and collective expression, using collaboration as «creative advantage» (John Kao).

7. The exploration of intelligence and creativity will be extended to a great diversity of competences, knowledge and experiences connected in network, with a horizontal hierarchical structure and with a sponsor or coordinator of competences.

The wealth of the intellectual potential of the network will be proportional to the quality, diversity and predisposition to share individual intellectual capital. It presupposes the definition of collective norms of conduct and responsibility in order to make the process operative and minimize «noise».

8. The areas of opportunity serve the development of functionalities, ${ }^{19}$ not the reverse.

By promoting diversity of competencies, the process can «pull» organizations with a productive vocation that can be associated with the business. In doing so, they may have a purpose different from that which presides over their reason for existing. ${ }^{20}$

9. There are no constraints at the outset, as distinctive competencies are not defined in advance.

The constraints caused by the constraints associated with traditional processes (market, technology, distribution) no longer make sense in this new, open and interactive process. The full opening of the field of hypotheses and possibilities frees creativity in the pursuit of innovation.

10. The technologies associated with production and distribution will be a consequence of the factors underlying the distinctive competencies to be defined. Technologies that meet these requirements will be selected.

The definition of the technologies necessary for the commercial viability of the «functionalities» depends on the process, that is, depends on the dynamics found for a given functionality solution. Once «distinctive competence» and hence «functionalities» are defined, it is possible to characterize, define or invent the technologies which incorporate or give it a body. This factor will determine which technologies to choose and not the inverse. However, there is nothing to prevent technology being invented, as nothing prevents industry from reinventing itself.

\footnotetext{
${ }^{19}$ Gary Hamel prefers the concept of «areas of opportunity» rather than «industries» and «features» rather than «products and services» [23]. The adoption of its proposal is linked to the semantic enlargement that new designations always presuppose.

${ }^{20}$ «Core ideology» should not change, whereas «core competence» can and should.
} 
11. The fragmentation of competencies and functionalities in components is privileged and shares are shared by alliance partners.

Irrespective of the stage at which the process is taking place, it is essential that all actors have an overall view of «distinctive competencies». When extending its scope to more actors, it is essential that the new specific knowledge stimulate shared knowledge, contributing to the enrichment of the collective (continuous learning). The fragmentation of competences does not mean that each one contributes to his or her knowledge in order to respond to part of the process: it means that each one contributes with all his knowledge to validate a shared concept for which he is especially well prepared.

12. The partners in the «areas of opportunity» (who may be coopetitors) may be geographically located anywhere on a global scale and selected primarily by their competencies.

This principle is a consequence of the locus-free business concept. Partners can be coopetitors because they can collaborate and compete simultaneously within the alliance: they collaborate because they are involved in it, they are part of it; compete because they can eventually offer competing products or services (on their own initiative remote hypothesis - because they are involved in other similar processes or because in the business partners with similar competencies are involved). Competence is a decisive factor for a given individual, organization or institution to be admitted as partners.

13. The end-users of the new «functionalities» are directly involved in detecting the opportunities for «distinctive competencies».

More than that, they are called from the outset to jointly build the strategic vision that gives shape to a certain «distinctive competence»: they are the soul of the strategic design vision.

14. Temporary alliances will be established around a certain distinctive competence.

As distinctive competencies will be defined, temporary alliances will be formed, depending on the individual knowledge of each partner and their suitability for the work to be carried out jointly.

15. The alliances will be constituted with well defined purposes, with individuals, groups of individuals, framed or not by organizations.

Innovation is the central purpose that should bring together the group of individuals around the alliance. ${ }^{21}$ The individual objectives, although they may be different from individual to individual or from organization to organization, should be governed by

\footnotetext{
${ }^{21}$ The same objectives identified by Chuck Martin apply, as they are also intended to create: «great brands on the Net [...] great products [...] usefull service [...] what is [not] expected [...] what is [not] needed [yet]» [19].
} 
the principles of interaction between the organization of creativity, the management of knowledge and the impact of new technologies (John Kao).

16. The capital required for the creation of «distinctive competencies» will be primarily the «intellectual capital» of each partner, but it may be necessary to ensure the participation of financial capital.

Intellectual capital underlies the process by being an integral part of the allies. The connectivity of knowledge workers in networks increases the intellectual capital invested by each ally. The financial capital that may be necessary for the development of the idea can be drawn from risk societies, institutional investors or individual investors. Investors who consider profit as a central purpose will be excluded from the outset. ${ }^{22}$ Those who take the investment as a natural consequence of a purpose of existence centered on audacious goals, but properly framed in the central purpose (humanization of the framework of life, work, leisure and rest) will be welcome.

17. «Intellectual capital» is measured in units of credit corresponding to units in «distinctive competencies». Efficient mechanisms will be found to measure the individual intellectual capital invested and to allow the conversion of this intellectual capital into credit units (financial capital).

This is a sensitive issue, which requires wide and participative discussion, although it is always possible to change what is established throughout the process. By involving the sharing of intellectual property, the right place to discuss and seek the solution is the network itself. ${ }^{23}$

18. It is not necessary for partners to enter all at the beginning of the business, or to stay in it to the end.

Just as the workers of knowledge are dynamic, so is the alliance. The continuous entry and exit of partners increases the knowledge which, in turn, is put at the service of alliance partners and, more comprehensively, of the consumers.

19. The interaction resulting from the application of the concept $f$ «think and act globally» allows the overlap of several stages, in time and space, with the consequent reduction of costs and optimization of results.

In this context, «thinking and acting globally» means working in multidisciplinary teams, locus-free, high performance, enhanced by the capacity for interaction that the new media and modes of collaboration enable. Thus, it is possible to «pull» the consumer into the process, developing with him and for him, one-to-one, innovative concepts; in the same way, what is created reaches the consumer, avoiding

\footnotetext{
${ }^{22}$ «Profits are the lifeblood of any business, but life consists of more than keeping the blood flowing; otherwise, it would not be worth living.» [26]

${ }^{23}$ Also in this case the concept of learning organization applies.
} 
intermediaries. In short, the process allows shortening the inputs and outputs, which is essential in face of global competition.

\section{The connection system also serves to continuously check the excellence of the functionalities.}

Connectivity and simulation technologies enable the sharing and verification of realtime information to define the distinctive competencies, test the effectiveness and sustainability of the concepts that characterize the functionalities, characterize and identify their specifications, and gauge the applicable production technologies. ${ }^{24}$

\section{There is a need to create a database to save ideas to use later.}

The amount of knowledge produced (at high speed) will feed the «ideas factory» (John $\mathrm{KaO}$ ), stored in a database of free access for partners, which can be reused in the future.

22. The aim is to stimulate creativity aimed at innovation and lifelong learning. Innovation, creativity and quality have no limits. They go through the way they integrate into the process, regardless of the results.

\section{Conclusions}

We have tried to establish the principles and purposes that underpin the proposed idea. We leave open the need (or not) to code another design method to apply it to the design processes triggered by the first process (the object of our research). On a provisional basis, we admit that the methodologies available to develop new «functionalities» ${ }^{25}$ could maintain their operationality, provided that adjustments were made that were necessary, albeit intuitively. ${ }^{26}$ To develop them, one would have to experiment with the proposed model and later theorize. We can not predict whether it would be possible (or even necessary) to develop this rationalization effort to apply it to such an open and

\footnotetext{
${ }^{24}$ «In the next decade, the most important new sense-making tools will be those that help people visualize and simulate. Visualization techniques reduce vast and obscure pools of data into easily comprehended images. And simulation systems will become intellectual training wheels for executives, allowing them to experiment with strategies in the forgiving world of cyberspace, in much the same way that pilots in the Gulf War ran practice missions before flying the real thing.» [26].

${ }^{25}$ We have already mentioned the scarcity of contributions, within the framework of methodologies that consider the profound changes in the production-consumption processes. Many methodological models produced in the 1960s and 1970s, long before the democratization of computer use (in design, production and sale) and the emergence of the medium that revolutionized this revolution - the Internet, are available. The most recent studies, especially those by German authors, point to the need to reflect on the methodological question but do not codify new processes. Thus, it would be useless to describe those available (Alexander, Jones, Bonsieppe, Löbach, Bürdek, Baxter, among others) to support the elaboration of a new theory of projection.

${ }^{26}$ It is not possible to determine whether it will involve grouping, skipping, flipping, or transforming the various steps. It is referred to the small article «L'intuizione del metodo» by Maria Sanmorì (1996) [27], in which the author questions the possibility of practicing a project without a codified methodology.
} 
ever changing process. There might be conclusive answers from their experimentation and the sharing of these concerns with some of the allies: we believed in the potentialities arising from the experimentation of the design process we proposed and the subsequent enrichment in terms of learning.

Enzo Paci's commentary on the occasion of the 3rd International Congress on Aesthetics (Venice, 1956) is particularly illuminating and prefiguring in this regard:

«One of the most serious dangers of the contemporary cultural situation is the intellectual projection of predetermined discourses, and of methodological plans, on the level of concrete experience. This is not to deny the value of methodology and technique. It only means that the technical and methodological tools should not be badly materialized and placed outside their field of application as if nature and the living experience of man were the matrix of every technique and method, but, at the on the contrary, a world extracted from the method is considered real instead of instrumental.» [28]

Acknowledgements. CITAD - Centro de Investigação em Território, Arquitetura e Design, Universidades de Lusíada, Portugal; CIAUD - Centro de Investigação em Arquitetura, Urbanismo e Design, Faculdade de Arquitetura, Universidade de Lisboa, Portugal.

This research is financed by national funds from the FCT - Fundação para a Ciência e a Tecnologia, Portugal, within the scope of the project UID/AUR/04026/2013.

\section{References}

1. Maldonado, P.: Design: uma visão estratégica (Design: a strategic vision). Msc Dissertation, Universidade do Porto (1997)

2. Maldonado, P.: Inspædia: design, inovação et cetera (Inspædia: innovation, design and so on). Lisboa: Universidade Lusíada Editora (2017)

3. Maldonado, P., Ferrão, L., Ermida, P.:"Inspædia: changing the landscape of cultural reflection and influence through user experience design”. In: Rebelo F., Soares M., eds. Advances in Ergonomics in Design. AHFE 2017. Advances in Intelligent Systems and Computing, vol. 588. Cham: Springer, 2018, pp. 462-468. doi: 10.1007/978-3-319-60582-1_46. (2017)

4. Maldonado, P., Teixeira, F., Duarte, J. P., Câmara, A., Correia, N., Ferrão, L., Ermida, P., Passos, M.: "Inspædia report: an inspired research itinerary". In: Rebelo F., Soares M., eds. Advances in Ergonomics in Design. AHFE 2017. Advances in Intelligent Systems and Computing, vol. 588. Cham: Springer, pp. 432-442. doi: 0.1007/978-3-319-60582-1_43. (2017)

5. Maldonado, P. et al.: Inspaedia [internet]. https://www.inspaedia.com (2016)

6. Maldonado, P. et al.: Inspædia: [almost] everything about simplicity, playfulness and inspiration. In: Soares, M. et al. (eds.) Advances in Ergonomics Modeling, Usability \& Special Populations, Advances in Intelligent Systems and Computing 486, pp. 231-243. doi: 10.1007/978-3-319-41685-4_21 (2016)

7. Maldonado, P., Teixeira, F., Silva, F.M., Ferrão, L., Ermida, P. \& Passos, M.: Inspædia user experience design (UXD). Procedia Manufactoring, 6th International Conference on Applied Human Factors and Ergonomics (AHFE 2015) and the Affiliated Conferences, vol. 3, pp. 6044-6051. doi.org/10.1016/j.promfg.2015.07.727 (2015)

8. Maldonado, P., Silva, F.M., Gonçalves, F.: Inspædia, Inspiring a Collaborative Intelligence Network: Designing the User Experience. In: Ahram, T., Karwowski, W. \& Marek, T. (eds) 
Proceedings of the 5th International Conference on Applied Human Factors and Ergonomics AHFE 2014, Kraków, Poland 19-23 July 2014, pp. 463-472 (2014)

9. Maldonado, P. \& Ferrão, L.: Inspædia: uma Rede de Inteligência Colaborativa Inspiradora (Inspaedia: a Collaborative Intelligence Network). Actas de Diseño - III Congreso Latinoamericano de Enseñanza del Diseño, Año VIII, vol. 15, pp.193-197. Universidad de Palermo, Buenos Aires (2013)

10.Maldonado, P.: Inovação, Design et cetera (Innovation, Design and so on). PhD Dissertation, Universidade Técnica de Lisboa (2012)

11. Maldonado, P.: Strategic Design: an Innovation and Design Process Flowchart. CIPED VI Congresso Internacional de Pesquisa em Design Livro de Resumos. CIPED VI Congresso Internacional de Pesquisa em Design, pp. 292-293. CIAUD, Lisbon (2011)

12. Handy, C.: A Era da Irracionalidade ou a Gestão do Futuro (The Age of Irrationality or the Management of the Future), Edições CETOP, Mem Martins (1992)

13. Rodrigues, J.N.: «Jamming com o Professor Kao», Executive Digest, Ano II, No 23, Lisboa, Sep. 1996 (1996)

14. Hammer, M.: «E depois da Reengenharia ?», Executive Digest, Ano II, N² 22, Lisboa, Aug. $1996(1996)$

15. Thurow, L.: «O Futuro do Capitalismo», Executive Digest, Ano II, Nº 18, Lisboa, Apr. 1996, (1996)

16. Lawson, B.: How Designers Think - the Process Demystified, $2^{\text {a }}$ ed., Butterworth Architecture, Oxford (1995).

17. Maldonado, T.: Disegno industriale: un riesame, $2^{a}$ ed., Feltrinelli Editore, Milão, (1992)

18. Margolin, V. (ed.): Design Discourse - History, Theory and Criticism, The University Press, Chicago (1989)

19. Martin, C.: The Digital Estate - Strategies for Competing Surviving, and Thriving in an Internetworked World, Mcgraw-Hill, New York (1997)

20. Rodrigues, J. N.: «A Internet tornou-se o Quinto Poder», Executive Digest, Ano III, No 35 , Lisboa, Sep. 1997 (1997)

21. Rodrigues, J. N.: «O Regresso da Gestão por Cenários», in Executive Digest, Ano III, Nº 27, Lisboa, Jan. 1997 (1997)

22. Oakley, M. (ed.): Design Management - A Handbook of Issues and Methods, Blackwell Reference, Oxford/ Cambridge (1990)

23. Gibson, R. (ed.): Rethinking the Future - Rethinking Business, Principles, Competition, Control \& Complexity, Leadership, Markets and the World, Nicholas Brealy Publishing, London (1997)

24. Kao, J.: Jamming - The Art and Discipline of Business Creativity, col. "Harper Business", Harper Collins Publishers, New York (1997)

25. Iansiti, M. West, J.: «Technology Integration: turning Great Research into Great Products», Harvard Business Review, Boston, May-Jun., 1997 (1997)

26. Drucker, P. et al.: «Looking Ahead: Implications of the Present», Harvard Business Review, Boston, Sep.-Oct., 1997 (1997)

27. Sanmorì, M.: «L' intuizione del metodo», Stile Industria, Ano II, No 7, Milão, Sep. 1996, (1996)

28. Morello, A.: «Alla ricerca di Enzo Paci - l' estetica, la tecnica e il loro rapporto con il mondo», Stile Industria, Ano I, Nº 3, Milão, May 1995 (1995) 